\title{
Perspectives on the Etiology of Violence in Later Life
}

\author{
Yuliya Mysyuk, MA, MSc,' \\ Rudi G. J. Westendorp, MD, PhD, ${ }^{2}$ \\ and Jolanda Lindenberg, PhD' $^{\prime}$
}

\begin{abstract}
This article focuses on the development of a conceptual framework for explaining the etiology of violence in later life by various groups involved in the field of elder abuse. In this study, we explore this through eight focus groups with different professionals involved in the field of elder abuse and older persons themselves and in interviews with 35 experts in the field. Our findings show that dependency, vulnerability, power and control, social isolation, stress, and care burden play a central role in their explanations for the occurrence of violence in later life. The role of a history of violence in violence in later life is equivocal. The complexity and ambiguity of dependency and vulnerability, the notion of mutual dependency, and diverse attitudes and expectations toward them that arise with the aging process are distinct features of violence in later life that were found.
\end{abstract}

\section{Keywords}

elder abuse, etiology, dependency, vulnerability

\footnotetext{
'Leyden Academy on Vitality and Ageing, Leiden, The Netherlands

${ }^{2}$ Center for Healthy Ageing, University of Copengagen, Copenhagen, Denmark
}

\section{Corresponding Author:}

Yuliya Mysyuk, Leyden Academy on Vitality and Ageing, Poortgebouw LUMC, Rijnsburgerweg 10, 2333 AA, Leiden, The Netherlands.

Email: mysyuk@leydenacademy.nl 


\section{Introduction}

Explanations for the occurrence of violence in later life that are often described in the literature focus on individual characteristics, interpersonal interactions and relationships, and factors related to the environment. Indeed, variables such as mental problems of the perpetrator including substance abuse, and dependency, social isolation, stress and overburdening, and power and control dynamics are important explanatory variables that have been identified (Anetzberger, 2004; Biggs, Phillipson, \& Kingston, 1995; Burnight \& Mosqueda, 2011; Phillips, 1986; Pillemer, 1986).

Violence in later life is differently viewed and experienced by various groups involved in the field of elder abuse. This raises the question of how violence in later life is understood and explained by those groups. By exploring the etiology of violence in later life through empirical data from expert interviews and focus groups of diverse stakeholders, we come to a conceptual model for explaining the etiology of violence in later life from the perspectives of the groups involved in elder abuse.

In this article, elder abuse refers to violence perpetrated by anyone in the environment of an older individual who is trusted by this individual and follows the definition of the World Health Organization (WHO). ${ }^{1}$ We do not use the age limit and instead adhere to the principle that abuse arises as a result of circumstances connected to age-related problems. The prevalence rate of elder abuse in the Netherlands was estimated at 5.6\% with 3.2\% for the prevalence of verbal aggression, $1.4 \%$ for financial exploitation, $1.2 \%$ for physical aggression, and $0.2 \%$ for neglect accordingly (Comijs, Pot, Smit, \& Jonker, 1998).

\section{Health Care in the Netherlands}

Our study was conducted in the Netherlands, a country known for having a rather elaborate social welfare system that includes quite an extensive amount of formal care for older individuals. This might affect the explanations of abuse we delve into. To situate our findings, and the way our participants explained abuse, we first give a brief introduction into the circumstances of older individuals in the Netherlands. Particular attention is given to care and support because this played an important role in the explanations of our participants.

Over the past 60 years in the Netherlands, there was a shift in responsibility for care of older persons from familial and informal care to institutional care (van Bodegom et al., 2010). Long-term care in the Netherlands is provided both in institutions (residential care) and in communities (home care). 
The residential care sector includes nursing homes and residential homes. Residential homes provide housing, care, help, and support for persons who cannot live independently. Nursing homes are principally for people with more severe conditions who require continuous care. However, the care provided in residential care facilities has become more complex over the years and nowadays the services between nursing homes and residential homes often overlap. In addition to residential and nursing homes, semiresidential care settings such as day care centers and short stay care centers provide care to individuals who still live in their own homes, but who have limited access to informal care (Organisation for Economic Co-Operation and Development [OECD], 2011; Schäfer et al., 2010). Older women more often live in institutional care facilities than men not only because the average life expectancy of females is higher but also because they traditionally marry men who are several years older (van Bodegom et al., 2010). Another form of care for older persons in the Netherlands is home care that includes home help, personal care, and nursing care at home, which is provided by different home care organizations or residential and nursing homes. To illustrate, in 2008, approximately $6.7 \%$ of the Dutch population older than the age of 65 received longterm care in an institutional setting while $12.9 \%$ of this population received long-term care at home (OECD, 2011).

Informal care is an important form of care in the Netherlands and can involve informal caregivers and volunteers. The number of individuals providing informal care has remained remarkably stable in the last decades; between $12 \%$ and $13 \%$ of Dutch older than the age of 18 provide informal care. The acknowledgment of the care and contribution these informal caregivers provide seems limited in the Netherlands (de Boer, 2005), and this is perhaps best illustrated with the "informal care compliment" that is a token of appreciation of the Dutch government for informal caregivers amounting to 200 euro annually. About $7 \%$ of those caregivers are heavily to very heavily burdened by the care they provide (de Boer, 2005). In addition, there are indications that due to demographic changes and the labor participation of females, the supply of informal care will not be sufficient for the demand of informal caregivers in the future. Both emotional and instrumental support (helping with housework, administration) are provided by caregivers. Emotional support rather than instrumental support seems to play an important role in the Netherlands among family members. Informal helpers are - in order of number of hours of informal care given according research in the Survey of Health, Ageing and Retirement in Europe (SHARE) study (Bonsang, 2009) - partners, children, other family members, and friends. Not only older persons who live at home but also the ones in care institutions receive informal care. Approximately, $40 \%$ of older people receive informal 
care (de Boer \& de Klerk, 2013; van Bodegom et al., 2010). About 4\% of older individuals live with their children in one house (de Boer, 2005).

\section{Method}

A qualitative study on the meaning, perceptions, ideas, and views on elder abuse was conducted among older persons, professional groups, and experts. The methods of data collection were focus groups and semistructured interviews. The aim of focus groups was to capture options and views of different groups on elder abuse to be able to understand how these groups define and explain elder abuse. Expert interviews were held to show how experts in the field, people who work with the problem, frame abuse. The interviews added to the knowledge obtained by conducting focus groups. Confidentiality and anonymity were guaranteed through an explicit oral agreement.

\section{Focus Groups}

Eight focus groups were conducted. The topics that were discussed were defining elder abuse and actions that could be performed to reduce its occurrence. We conducted separate focus groups with experts (seven persons: five females and two males), policy makers (six persons: five females and one male), managers of health care organizations (seven persons: three females and four males), interest organizations of older persons (three persons: two females and one male), physicians (four persons: three females and one male), professionals from institutional (four persons: four females) and home care (four persons: four females), and older people themselves (seven persons who had no experiences with abuse: four females and three males). In total, 42 participants were included. The focus groups lasted between one and two and a half hours; by and large, this seemed to depend on the number of participants. The groups were homogeneous in professional background, however, heterogeneous in gender and age, except for the focus groups of institutional and home care. During the focus groups, a protocol was followed that included the introduction of the purpose of the focus group, the main rules, starting and leading of discussion, the main questions and how to deal with challenging moments (see Appendix A for the protocol). The list with potential participants for the focus groups was made on the basis of known organizations in the Dutch field of elder abuse. Then, persons from different organizations involved in the field of elderly care were added to the list and asked for further referral and potential participants. Recruitment of older persons was through senior citizen organizations in the Netherlands. Prescreening of older persons regarding their experiences with abuse was 
done by telephone. Following this, all other potential participants were contacted via emails and phone calls and invited to take part in a particular focus group based on their position, expertise, experience with abusive situations, and skills. This was checked in a telephone conversation preceding the focus groups. All participants were informed of the purpose of the focus groups. Before the start of the focus groups, permission was asked for recording. The focus groups took place between February and March 2012 and were transcribed verbatim.

\section{Interviews}

Thirty-five expert interviews (six males and twenty nine females) with diverse professionals who work in the field of elder abuse were conducted. The experts included academics, managers of health care facilities, professionals from public health services and support centers for domestic violence, elderly advisors and case managers, and police officers. The experts in the field were identified through different organizations in research, elderly care, and elder abuse fields. Furthermore, they were approached through contact persons via a snowball sampling technique. The experts were considered as such based on their experience with elder abuse, and/or special knowledge and expertise related to the field of elder abuse. During the interviews, the discussion focused on how cases of abuse were identified, assisted, and followed up. The semistructured expert interviews were held by guidance of a topic list. The topics and the questions of the topic guides were developed based on existing research literature on elder abuse and also with help of pilot interviews with some experts conducted before the study, as well as discussions and debates with experts and professionals.

The topics and the questions of the interview guide were developed based on existing literature on elder abuse and on findings obtained from the focus groups. The topics of the interview guide included background and meaning of elder abuse, profiles of victim and perpetrator, collaboration and network, perspectives of wider society, and necessary actions to deal with elder abuse (see Appendix B). The expert interviews lasted between one and one and a half hour. The interviews took place between December 2012 and April 2013. All interviews were transcribed verbatim for analysis.

\section{Analysis}

Verbatim transcripts of the interviews and focus groups were comprehensively and systematically analyzed using the computer software NVivo. The approach used for analyzing data was primarily inductive, in which analytical 
concepts and perspectives are derived from the data through a coding technique based on a grounded theory approach (Glaser \& Strauss, 1967 ). First, the text was divided in segments that discussed the same theme (content analysis). Second, through interpretative analysis concepts were indicated with codes, then the concepts that emerged from the codes were used to develop the main categories that served as the basis for exploring and discussing the views and experiences of the respondents. Such an approach allows exploring the ways in which respondents explain their own experiences and also permits unexpected topics, issues, and thoughts to emerge.

\section{Results}

We identified the following concepts that play a role in explaining the etiology of violence in later life and its associated factors according to our participants: dependency, vulnerability, power and control, social isolation, stress and burden, and history of violence.

\section{Dependency}

Loss of autonomy and increasing dependency in old age are seen by experts as the most important issues that can influence the occurrence of violence. Experts and professionals usually meant relying on other people for assistance or care when they referred to dependency of older persons; this could be in the physical, economic, social, or psychological domain. Older persons can become dependent on their children or other family members. Different forms of dependency that are present in later life put older persons even more at risk of violence. A similar opinion was expressed by one of the participating professionals:

Dependency is often present. Dependency on the perpetrator, and this can be dependency because of housing, financial dependency, emotional dependency, dependency on care and help . . . In my opinion dependency plays a role in abuse, it is a risk factor for abuse. (Focus group "Institutional care")

Professionals, especially in the group of physicians and home care, pointed out that not only the victims are dependent on their abusers but often also the perpetrators can be dependent on their victims. One professional from extramural care stated it as follows: "In my experience, very often abusers are dependent on the older persons, they do not have their own house, normal job and means of living." Our participants saw mutual dependency as a common and determining feature of elder abuse. 


\section{Vulnerability}

A concept that was discussed as important in several focus groups and interviews was the notion of vulnerability. Similar to dependency, vulnerability was seen as having different forms. One of the participating policy makers described,

You can observe different types of vulnerability, for example, psychological or physical. In a case of financial abuse the person is not able to do his or her own administration and somebody else has to do it for him or her, this makes this person per definition vulnerable.

Thus, an inability to perform daily tasks or limited opportunities to remain autonomous and independent poses potential risks to become exposed to stressful situations in which abuse can occur. According to expert opinions, dependency and vulnerability are distinct but interrelated concepts:

... we see older people as vulnerable and dependent, they go together, they are connected. If we think about older persons the first idea that comes to our mind is that the elderly are fragile, weak and dependent. That's the image that a lot of people have about older persons. (Interview, expert public health sector)

Older people shared this notion of vulnerability and dependence. For them being vulnerable leads to dependency and at the same time is a consequence of being dependent and they are afraid of losing their independence, as one older participant formulated it: "you are vulnerable when you are dependent on others" (Focus group "Older persons").

At the same time, however, we obtained contradictory results from the focus groups, showing that older people themselves sometimes refrain from using the word "vulnerable" to describe a situation that in other groups would be described as such. Rather, older people see vulnerability as a concept that has a negative connotation putting them in a dependent position and presenting them as incapable, weak, and impaired. Older persons describe that you can be vulnerable only when you yourself feel vulnerable and fragile; otherwise, it is just the perception of other people. They argued that often other people see and present older persons as frail and vulnerable, in spite of the fact that according to older people they would not consider themselves as being so (focus group "Older persons"). Older persons sometimes see vulnerability as a social artifact, something that is imposed on them by the outside world basically because they have aged. At the same time, experts see vulnerability as something related to older persons and to the occurrence of abuse, making vulnerability an especially contested and ambiguous concept. 
The conceptualization of vulnerability becomes more complex as professionals often saw this concept as something that can be applied to different age groups, as one expert from the local government phrased it: "We can all be vulnerable at different times in our life" (interview expert local government). It seems that our participants viewed the condition of vulnerability as neither age specific nor age related; everyone can be seen as vulnerable to some degree.

\section{Social Isolation}

The concepts of dependency and vulnerability were often mentioned together with the role that social isolation played in cases of elder abuse. Professionals, especially in the group of experts and policy makers, voiced assumptions and ideas about social isolation as a contributor to circumstances in which abuse can occur. Social isolation was seen as a lack of support from family, friends, or neighbors and a lack of established social networks. One of the experts stated this as follows: "Social isolation is a basis for abuse. Being alone, having no social contacts, no social networks can eventually lead to abuse." One of the interviewees pointed out that there is an association between social isolation and loneliness: "I think that loneliness plays a big role, older people are lonely and isolated. What I often see and observe is loneliness, isolation and dependency." Other respondents shared this idea. Thus social isolation is often linked to loneliness and financial or psychological dependencies.

Experts in the focus groups not only discussed the idea of isolation as a contributor to abuse but also as a consequence of abuse. They described that as a result of the experienced abuse, some people do not want to go out or socialize, and as a result, withdraw from their community and become isolated and feel lonely. One of the experts pointed out that "elderly are often isolated, they are alone with the abuser since the abuser is someone whom they know and the other contacts are just excluded." It makes it more difficult to detect abuse and to change such a situation: "It seems like older people are locked in a vicious cycle, not seeing other opportunities and ways out" (expert from nonprofit organization). Social isolation is therewith at the same time a cause and a consequence of violence in later life.

\section{Stress and Burden}

Besides the web of dependencies sketched above, both professionals and older persons mentioned many issues of stress and burden experienced by the perpetrator. These included lack of time, lack of privacy, difficulties in relationships, and decreases in financial recourses. Stress and burden seem to be 
conceptualized as predependency issues. Some of the interviewees pointed to a combination of different factors that can lead to stress and eventually accordingly can lead to violence. Possible contributors that were mentioned in this context were unemployment, substance abuse, and problems in the family that could each contribute to the development of stress. One of the respondents from the focus group "physicians" phrased it as "Stress and overburdening are very common, in particular when one person is caring for another one. It can be overburdening to provide care" and from the findings of de Boer (2005), we know that, at least, for $7 \%$ of the carers in the Netherlands, the care provision is indeed considered a heavy to very heavy burden. The findings from the focus groups and interviews show that the predominant image of elder abuse is one of a dependent older person, who becomes a difficult burden to her or his adult child who abuses or neglects the older person in response to stress and frustration.

\section{Power and Control}

Through the multiple losses of power that can occur during the aging process, older persons can feel that they are burdening others. One of the older persons phrased it as "older persons feel powerless, they do not wish to bother others." These shifts in power combined with dependency and vulnerability increase the feeling of older persons that they are disturbing others and make them feel redundant. The powerlessness they experience also has its impact on the experience of power and control feelings of the perpetrator.

Professionals from different focus groups pointed out that there are different reactions of an older person to a lack of power, such as acceptance and adaptation, or denial and resistance. The decrease in power they experienced in the relationship with the abuser and their reactions to this loss of power seemed to be influenced by older persons' perspective of being unnecessary for society, especially in the case of adaptation and acceptance. Some of these reactions may cause frustration to an older person and to a perpetrator and these were seen as perhaps bringing on (further) violence on the side of perpetrator. These ideas of professionals come close to the views of older persons. "A lot of older people just do not react to an abusive situation, they just ignore or accept it" stated one of the participants in the focus group "Older persons."

Loss of power is an important factor in violence in later life; experts felt that this was not only the case for older persons but also for perpetrators. Respondents from the focus group of policy makers described that "Powerlessness and incapacity can lead to abuse, the abuser is trying to increase his or her power and control by using abuse." One of the experts saw 
the issues of power and control imbalance as follows: "He [perpetrator] is going to abuse because of a lack of power, incapacity and inability to cope with the situation. This is self-evident." Accordingly, abuse can occur as a response to a lack or loss of power not only of the older person but also of the perpetrator in which case there is dependency of the perpetrator on an older person. A perpetrator uses violence to gain power and control, and dominance in the relationship. Thus, the participants in our study viewed the feelings of powerlessness or powerfulness of the perpetrator in the relationship with the victim as one of the crucial explanations why perpetrators start using violence and saw this mainly as an effort to restore or enhance power and control.

\section{History of Violence}

Professionals and experts who work in the field of elder abuse expressed the opinion that violence is learned behavior. An expert from the local authorities described it as follows: "Experiences of violence during childhood or being raised in a situation of family violence or being familiar with violence can be a risk factor for violence in later life." Participating experts explained violence in later life as a learned behavior that was transmitted from one generation to the next.

The opposite opinion was expressed by some of our participants. One of the experts from the research field doubted whether violence is transmitted from generation to generation. The expert concerned said, "It is not evident whether violence is learned behavior. I would rather argue that only in some cases this is true. [But], we know about different studies that prove the opposite." Other respondents agreed to that, pointing out that violence in later life is occurring mostly without prior history of violence during childhood. These two opposite views expressed by our respondents - in particular experts and professionals - show that the contributory role of a history of violence in the explanation of elder abuse is still debated.

\section{The Etiology of Violence in Later Life}

All the concepts discussed above have interrelationships according to our participants, thus making the picture of violence in later life as envisioned by our respondents rather complex. In Figure 1, we have portrayed these interrelationships to provide a model for understanding violence in later life from the perspectives of older persons, experts, and professionals.

The complexity becomes especially vivid for the concepts of dependency and vulnerability; their different forms are linked together, their occurrence 


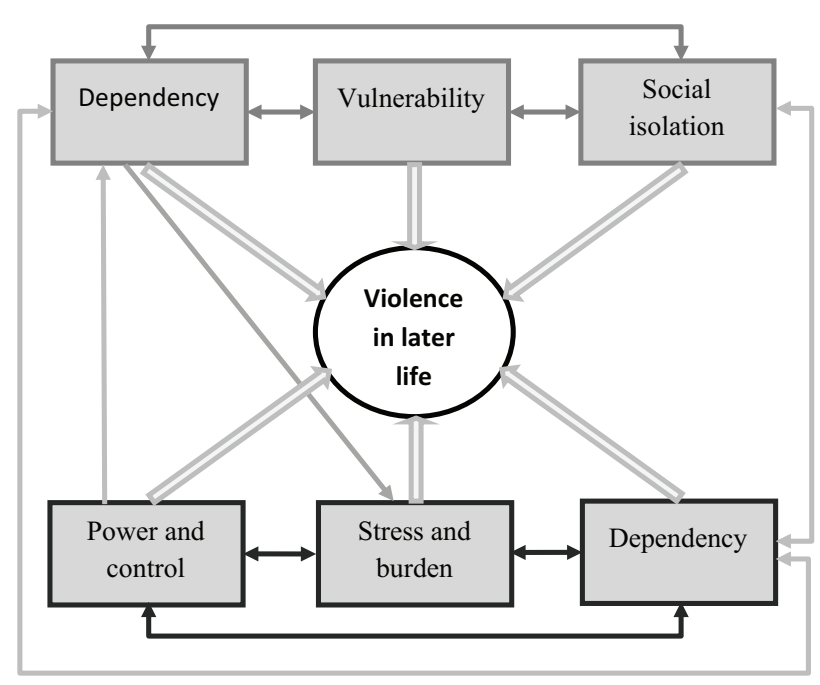

Concepts related to victim

Concepts related to perpetrator

Figure I. Relationships between concepts.

influences each other and at the same time the two seem to complement each other. Concurrently, vulnerability can cause dependency, which can cause violence. Caregivers who care for a vulnerable and dependent older person or who themselves are dependent on an older person are not always able to manage their responsibilities and cope with stress in an effective way. In a lot of cases, a victim is isolated by a perpetrator from the outside world, feeling lonely and socially excluded (Bennett, Kingston, \& Penhale, 1997; Biggs et al., 1995). Hence isolation and loneliness are important (interrelated) circumstances for the development of violence in later life. Social isolation, in addition, may not only be a cause but also a consequence of dependency of either the victim or the perpetrator, which again can be the result of vulnerability. The dependency of victim and perpetrator, vulnerability and social isolation of a victim, and caregiver's stress are closely related to power and control inequalities, which determine the imbalance experienced in the victim-perpetrator relationship. 
It is important to mention the way our participants tied different factors together in their explanations of the occurrence of abuse, namely, the web of dependencies and its relationship with the aging process and the ambiguity expressed by older participants about dependency and vulnerability.

\section{Discussion}

Through our empirical data, we have explored different perspectives on the etiology of violence in later life by the groups involved in elder abuse. We established that the main concepts presented above were discussed by all the groups included in our study as important in explaining the etiology of violence in later life, with the exception of a history of violence, which was mainly mentioned in the professional focus groups and in the interviews with experts. According to our participants, several concepts, dependency, vulnerability, and social isolation were interrelated and influenced each other. Thus, we identified that all groups in elder abuse shared a similar understanding of the etiology of violence in later life. There is, however, some ambiguity around the conceptualization of vulnerability and the role of a history of violence.

\section{Dependency}

The views of the participants in the focus groups of professionals, older people, and experts about the dependency of older persons on their abusers is confirmed by some studies that suggest that older people who are dependent on their caregivers, family members, other relatives, or friends seem to be at greater risk of becoming victims of violence (Douglass, Hickey, \& Noel, 1980; Pillemer, 1986). Some studies also show that reverse dependency (perpetrators on their victims) can exist, such as also proposed by some of our participants. It is argued that abusers can be dependent on older persons for financial, emotional, or social support (Kosberg \& Nahmiash, 1996; Pillemer, 1985). It is, however, also posited that dependency takes the form of mutual dependency, where perpetrators are dependent on older persons, and in turn, older people are dependent on their abusers. These multiple dependencies may cause an imbalance in rewards and control, meaning that older persons are less able to contribute to the relationship in any positive way, increasing the stress of the caregiver and the costs of relationship and maximizing the risks of violence to occur (Phillips, 1986; Pillemer, 1985).

Dependency is generally seen as a crucial factor in violence in later life, but it is not yet clear who is depending on whom in these abusive relationships. We establish that dependency in later life is a complex concept that can have 
different bases (psychological, physical, or economic dependency) and causes; it can be related to the victim or the perpetrator creating mutual dependency. More important, dependence seems to have negative connotation, as older individuals are expected to be mature, independent adults while bodily decline during the aging process often puts them inescapably dependent on others. These characteristics of dependency that seem related to specificities of the aging process make violence in later life distinct from dependency in other stages of life in which family violence can occur.

\section{Vulnerability}

The perceptions of experts and older persons about the interrelation between dependency and vulnerability are in line with some literature findings on elder abuse that state that there is a relationship between dependency and vulnerability, especially for older persons (Roberto, Teaster, \& Duke, 2004; Stevenson, 2009). Moreover, from the findings of study, it emerges that older persons see vulnerability as hazardous because it can contribute to dependency. They also consider vulnerability to have a negative connotation that is sometimes imposed on them by society. Different studies confirm the view of the experts from our study; older people seem to be more susceptible to specific challenges (in terms of health, income, and social roles) and vulnerability entails that they have reduced capacity to respond to them (Grundy, 2006).

The ambiguous feelings around the meaning of vulnerability and in particular its meaning for older persons as described above in the empirical data, the existence of different forms of vulnerability, and its relationship with dependency are important elements that have to be taken into account when we discuss violence in later life. The general concept of vulnerability seems to have a specific meaning in the context of elderly in which vulnerability occurs because of increasing physical frailty associated with aging (Slaets, 2006). More important, the ambiguous feelings around the meaning of vulnerability as imposed by others and in particular its meaning for older persons as described above are aspects that should be taken into account and are important considerations in which elder abuse is quite different from family violence at other stages of life.

\section{Social Isolation}

The views of professionals about the role of social isolation in violence in later life are confirmed by some studies that show that social isolation is a characteristic of families in which child, spouse, and elder abuse occurs (Pillemer, 1986 ; Pillemer \& Finkelhor, 1988). Social isolation of an older 
person and caregiver is associated with increased risk for elder abuse (WHO, 2002).

One of the crucial features of social isolation is that it can be, at the same time, a cause and a consequence of violence in later life. Based on the views of experts and professionals, it is generally argued that the concepts of social isolation, loneliness, and lack of support are related to each other and influence each other. However, theoretically it has been argued that violence in later life causes social isolation (Pillemer, 1986).

\section{Stress and Burden}

Besides the other variables discussed above, the respondents also mentioned the issues of stress and burden. Our findings from interviews and other studies outline that stress can occur due to internal or external factors and accumulation of stresses can lead to overload that can result in abuse (Bennett et al., 1997; Block \& Sinnott, 1979; Galbraith \& Davison, 1985). Some studies even show that actual stress may be a less important predictor of violence than the caregiver's perception of stress (Steinmetz \& Amsden, 1983; Zarit, Reever, \& Bach-Peterson, 1980). The ideas expressed in focus groups and interviews that stress and overburdening are common in caregiving situations and can lead to abuse are also present in the literature. Indeed, violence in later life is often considered as a result of an inability to cope with stress occurring from caring for an older person. Therefore, caregiving is often seen as a burden that is not possible to bear (Burnight \& Mosqueda, 2011; Wolf, 2000).

The issues of stress and burden are closely related to the perpetrator. Stress and overburdening of the caregiver can lead to abusive situations (Bennett et al., 1997; Hyde-Nolan \& Juliao, 2012). The concepts of dependency and vulnerability of both victim and perpetrator are interrelated and influencing the possible occurrence of stress and the possible resultant abuse.

\section{Power and Control}

The views of professionals and experts in our study about possible reactions of compliance and acceptance to abuse that older persons can demonstrate are confirmed by findings in the literature showing that some older people experiencing violence can react to a situation of abuse by becoming more compliant and this can sometimes provoke more abuse. In the literature, this phenomenon is described as "learned helplessness" (Miller \& Seligman, 1975, p. 228). Seligman mentioned that helplessness produces emotional distress. There is no motivation to respond to the situation if the individual feels nothing can be done to affect the outcome (Quinn \& Tomita, 1997). 
The ideas about the attempts of perpetrator to restore his or her power and control by using violence that were expressed by different experts are in line with other studies that described that perpetrators may use various tactics to gain lost power and control of their victims, one of which is abuse (Bancroft, 2002; Biggs \& Haapala, 2010; Biggs et al., 1995). Abusers' thinking patterns lead them to believe their needs are more important than others and that they can use any method necessary to get what they want and desire (Bancroft, 2002). Pillemer (1986) suggested that the feeling of powerlessness experienced by an adult child who is dependent on an elderly parent(s) may be critical because it is against society's expectations and norms that believe that adults should function independently and autonomously. In these abusive situations, the individual may use violence and act out of weakness. Again, the importance of powerlessness and loss of control is interrelated with issues of dependency and vulnerability.

\section{History of Violence}

In our study, we have found that a role of a history of violence in the occurrence of elder abuse is quite equivocal. Most of our informants, in particular, the experts from academia, did express ideas about elder abuse occurring mostly without prior history of violence. These opinions resemble the findings of some studies within the field of elder abuse that family history plays a less central role in the occurrence of elder abuse than, for instance, in family violence at other stages of life. These studies suggest that violence in later life occurs at best only in a minority of cases due to learned behavioral patterns in the context of the family (Korbin, Anetzberger, \& Austin, 1995; Pillemer, 1986; Thornberry \& Henry, 2013). These views are also congruent with the results from a study conducted by Pillemer (1986), who found no association between being abused as a child and becoming an abuser later in life (Korbin et al., 1995; Pillemer, 1986; Thornberry \& Henry, 2013).

The opposite perspective suggesting that elder abuse may occur due to previous history of violence in the family was also expressed by some of our participants, in particular by some older persons and experts. This view that individuals who are abused in childhood grow up to become abusive parents and violent adults has been discussed extensively within the family violence field (Burgess, Hartman, \& McCormack, 1987; Gelles, 1980; Starr, 1988; Straus, Gelles, \& Steinmetz, 1980; Walker, 1984). Some studies also suggest that violence in later life is more common in families with established patterns or histories of violent behavior and violence may be a consequence of learned responses (Fraser, 1996; Kosberg \& Nahmiash, 1996; Nadien, 1995; Owen \& Straus, 1975).

Thus, based on our data and insights from prevalence studies, it appears that there is not unequivocal evidence for the hypothesis that violence in later 
life occurs through a modeling of behavior that was observed earlier in life. Thus, still divergent views exist about violence as learned behavior that is passed on through generations.

\section{Limitations}

In this study, we used different qualitative methods of data collection. Nevertheless, the results from this study were based on a nonrepresentative sample. Consequently, some of the findings cannot be generalized to the whole population. However, our primary aim was to explore the perspectives on the etiology of violence in later life of diverse groups involved in elder abuse, and therefore, a qualitative research design to explore these explanations was more suitable for the purpose of the study. For future studies, we recommend that the current study will be extended and a systematic review on the theoretical perspectives of elder abuse and family violence will be added to establish how they differ and how particular theories are used in explanation of violence at different stages of life.

\section{Conclusion}

Our findings show that our participants explain elder abuse as a complex problem in which the variables dependency, vulnerability, social isolation, stress and burden, power and control, and history of violence play a central role in why abuse happens. The identified variables are interrelated. The role of a history of abuse in the occurrence of elder abuse appeared equivocal. Our study provides insights into the understanding of the etiology of elder abuse from the views of different groups involved in the field of elder abuse. We also established that different degrees and reversed issues of dependency and vulnerability, the notion of mutual dependency, and diverse attitudes and expectations toward them are distinctive features in the explanations of violence in later life.

\section{Appendix A}

\section{Focus Groups' Protocol/Guide}

Welcome!

\section{Introduction}

The topic that we would like to discuss today is elder abuse. We are interested in your opinion about elder abuse.

The results of this focus group will be used only for research purposes. 
Today I am your discussion leader. To begin with, I would like to introduce myself ...

As discussion leader/facilitator, I will try to make sure that we will listen to each other, respect each other, and give each other space. Your opinions, so variable as possible, are important for us to come to a better understanding about what we can do about elder abuse and what elder abuse is about. I am here to facilitate the discussion and to pay attention that we are remaining within the time frame/within the time.

Starting point/premise is that there are no wrong answers, only different opinions that I, as a discussion leader, will be pleased to hear.

Information package: folders (brochures about the institution, pen, notebook, and gift voucher of . . . euro).

Rules. I would like to introduce a few rules:

- For the research purposes, we are going to record focus groups. The recording is aimed only for transcription and analysis and will be used only for the research purposes. In the transcript, we will feign the names.

- We would kindly ask you to give the word to one person at the same time for better quality of the recording.

- "First name rule": To put you at ease, we would like to call you by your first name. Does anyone object?

- Listen to each other, give each other space, respect each other.

- Talk to each other.

The most of you know each other but not everyone. That is why I would like to start with an introduction round.

\section{Opening}

Can you please introduce yourself? Your name? Your background? What is your profession? What do you like to do during your free time?

If people know each other. This group is familiar with each other, that is why anonymity is not anymore possible but it is important to remember that everything that will be said here is confidential. Emphasis: confidentiality.

This group is not very familiar with each other, it is important to remember that everything that will be said here is confidential. Now we are sitting next to each other and we are not anymore anonymous but let us try to keep in this setting everything that will be said here. 


\section{Topics for Discussion}

Main topics

1. What do you consider as elder abuse?

- Definitions, meaning of the term;

- Forms of elder abuse.

2. What is necessary to be done to solve the problem?

- Actions (interventions, campaigns);

- Awareness (policy makers, general public);

- Different (social) aspects (quality of life, social life). Are there other aspects?/And social aspects?

\section{Possibilities of Ending Focus Group}

- Is there something that we have missed? Is there something that was not mentioned?

- Resume of discussion (OR) remind important points (2-3 min).

Asking about additions/comments/remarks/questions

Follow up (article or report)

- Thanking the participants

- Expense statement

- Have a nice trip back

For researchers: 10 min of debriefing

\section{Probes and Clarifying Questions}

I don't understand it completely. Can you explain it please?

Can you please explain it?/Illustrate it? Explain further?

How does it work?

Could you please tell us more about it?

Can you give an example?

Who has something to say?

Based on which experiences are you saying that?

What exactly do you mean?

Can you please describe what you mean? 


\section{To Lead the Discussion}

Would anybody like to react on this?

Does anybody have something to add to that?

Would anybody like to add something to that?

Does anybody see this differently? Does anybody think differently about it/ that?

Are there different views? How the others are thinking about it?

I see some people nodding, can you please tell me about it? Somebody has something different?

Silence: $5 \mathrm{~s}$, taking time to think about the answer;

Repeating the question;

As there is no answer: Why is this question so difficult? Not possible to answer?

\section{Redirecting}

Back to the question: Thank you for sharing that, but I would like to go to another aspect.

Thank you. It is an interesting comment. We have discussed this aspect. I would like to ...

This is an interesting discussion but we have to go further ...

\section{Dealing With Challenging Participants}

"Macho behaviour": We are here not to come to an agreement but to listen to different opinions.

Talking together: Sorry, I cannot hear you. I would like to ask you to talk only one at a time (for recording).

Somebody who is dominant: You have without any doubt a lot of experience; now I would like to hear something from the others. Do the others also have experiences? Has anybody given remarks? Do the others think differently? Would anybody like to add something?

\section{Appendix B}

\section{List of Topics (Expert Interview)}

\section{Introduction}

I am a researcher at the Leyden Academy. I am investigating elder abuse in the Netherlands. I am a sociologist. I studied Public Health in Maastricht. I 
am currently conducting my research at the Leyden Academy on Vitality and Ageing. This interview is a part of my qualitative study on perspectives of elder abuse. The aim is to get a better understanding of the issue of elder abuse by elucidating the background of abuse and explaining the factors that influence elder abuse. I am trying to obtain an overview of experiences of elder abuse.

The information will be used for research purposes only. All that you say will remain confidential. Anonymity will also be guaranteed. I will not use your name/place of work/occupation or any of your other identifying characteristics. Would you mind if I use a recording device? Alternatively: Would you mind if I record this interview?

I ask you this because I want to represent your words as truthfully as possible. I will type out the recording and use this for my analysis. The recording will not be used for any other purposes nor will it be listened to by the others.

\section{Background Information}

Could you (please) introduce yourself?

Sex (observe)

Education: What training have you received? Workplace: Where do you work?/Could you describe your position here/What you do here?

Experience: In what way do you involve yourself with elder abuse? What is your experience with elder abuse?

\section{The Background and Meaning of Elder Abuse}

What is the prevailing view on elder abuse within your practice/field of work?

Do you make use of a definition of elder abuse? If so, what is the definition?

What kind of behavior do you consider as abuse?

What forms of elder abuse have you come into contact with? What factors, in your opinion, play a role in elder abuse?

Could you please describe signals of elder abuse? What do you consider to be signals of elder abuse?

How often did elder abuse occur here in the past year?

How does this compare with previous years? What do you think influenced this?

\section{Profile of the Victim}

What characteristics do you find typical for a victim? What similarities do you see between victims? 


\section{Profile of the Perpetrator}

What characteristics do you find typical for a perpetrator? What similarities do you see between perpetrators?

\section{Collaboration/Network}

What do you do when you encounter a case of elder abuse? What is the plan of actions/procedure in the case of elder abuse? Could you please describe this? When you encounter a case of elder abuse, which aspects of the situation do you try to influence first? Where do you start? (Aspects: Which circumstances of the situation/of the older person do you try to influence first?) What is important?

From whom do you receive help, advice, and support? With what organizations do you work together? What organizations are involved?

\section{Societal Views}

How do people react to your line of work/profession when you introduce yourself?

In general, how do people react when elder abuse is mentioned?

\section{Necessary Action (Interventions, Prevention)}

What do you think needs to be done to reduce the problem?

What kind of preventive actions/interventions are still necessary?

Ending

Contact information

Gift

\section{Declaration of Conflicting Interests}

The author(s) declared no potential conflicts of interest with respect to the research, authorship, and/or publication of this article.

\section{Funding}

The author(s) received no financial support for the research, authorship, and/or publication of this article.

\section{Note}

1. Elder abuse is a single, or repeated act, or lack of appropriate action, occurring within any relationship where there is an expectation of trust, which causes harm or distress to an older person. 


\section{References}

Anetzberger, G. (2004). The reality of elder abuse. Clinical Gerontologist, 28(1), $1-25$.

Bancroft, L. (2002). Why does he do that? New York, NY: Berkley Books.

Bennett, G., Kingston, P., \& Penhale, B. (1997). The dimensions of elder abuse: Perspectives for practitioners. London, England: Macmillan.

Biggs, S., \& Haapala, I. (2010). Theoretical development and elder mistreatment: Spreading awareness and conceptual complexity in examining the management of socio-emotional boundaries. Ageing International, 35, 171-184.

Biggs, S., Phillipson, C., \& Kingston, P. (1995). Elder abuse in perspective. London, England: Open University Press.

Block, M., \& Sinnott, I. (1979). The battered elder syndrome. College Park: University of Maryland Press.

Bonsang, E. (2009). Does informal care from children to their elderly parents substitute for formal care in Europe? Journal of Health Economics, 28, 143-154.

Burgess, A., Hartman, C., \& McCormack, A. (1987). Abused to abuser: Antecedents of socially deviant behaviors. American Journal of Psychiatry, 144, 1431-1436.

Burnight, K., \& Mosqueda, L. (2011). Theoretical model development in elder mistreatment. U.S. Department of Justice. Retrieved from https://www.ncjrs.gov/ pdffiles1/nij/grants/234488.pdf

Comijs, H., Pot, A. M., Smit, J., \& Jonker, C. (1998). Elder abuse in the community: Prevalence and consequences. Journal of the American Geriatrics Society, 46, 885-888.

de Boer, A. (Ed.). (2005). Kijk op Informele Zorg [A look at informal care]. Den Haag, The Netherlands: Sociaal en Cultureel Planbureau.

de Boer, A., \& de Klerk, M. (2013). Informele zorg in Nederland. Een literatuurstudie naar mantelzorg en vrijwilligerswerk in de zorg [Informal care in the Netherlands. A literature study on caregiving and volunteer work in the care]. Den Haag, The Netherlands: Sociaal en Cultureel Planbureau.

Douglass, R. L., Hickey, T., \& Noel, C. (1980). A study of maltreatment of the elderly and other vulnerable adults. Unpublished manuscript. Ann Arbor, MI: Institute of Gerontology, University of Michigan.

Fraser, M. (1996). Aggressive behavior in childhood and early adolescence: An ecological-developmental perspective on youth violence. Social Work, 41, 347-361.

Galbraith, M., \& Davison, D. (1985). Stress and elderly abuse. Focus on Learning, 1(9), 86-92.

Gelles, R. (1980). Violence in the family: A review of the research in the seventies. Journal of Marriage and Family, 42, 873-885.

Glaser, B., \& Strauss, A. (1967). The discovery of grounded theory: Strategies for qualitative research. Chicago, IL: Aldine Transaction.

Grundy, E. (2006). Ageing and vulnerable elderly people: European perspectives. Ageing \& Society, 26, 105-134.

Hyde-Nolan, M., \& Juliao, T. (2012). Theoretical basis for family violence. In R. S. Fife \& S. Schrager (Eds.), Family violence: What health care providers need to know (pp.5-16). Mississauga, Ontario, Canada: Jones \& Bartlett Learning. 
Korbin, J. E., Anetzberger, G., \& Austin, C. (1995). The intergenerational cycle of violence in child and elder abuse. Journal of Elder Abuse \& Neglect, 7, 1-15.

Kosberg, J., \& Nahmiash, D. (1996). Characteristics of victims and perpetrators and milieus of abuse and neglect. In L. Baumhover \& S. Beall (Eds.), Abuse, neglect and exploitation of older people: Strategies for assessment and intervention (pp. 31-49). London, England: Jessica Kingsley.

Miller, W., \& Seligman, M. (1975). Depression and learned helplessness in man. Journal of Abnormal Psychology, 84, 228-238.

Nadien, M. (1995). Elder violence in domestic settings. In L. Adler (Ed.), Violence and the prevention of violence (pp. 177-190). Westport, CT: Praeger.

Organisation for Economic Co-Operation and Development. (2011). Help wanted? Providing and paying for long-term care. Paris, France: Author. Retrieved from http://www.oecd.org/netherlands/47877903.pdf

Owen, D., \& Straus, M. (1975). The social structure of violence in childhood and approval of violence as an adult. Aggressive Behavior, 1, 193-211.

Phillips, L. (1986). Theoretical explanations of elder abuse: Competing hypotheses and unresolved issues. In K. Pillemer \& R. Wolf (Eds.), Elder abuse: Conflict in the family (pp.197-217). Dover, MA: Auburn House.

Pillemer, K. (1985). The dangers of dependency: New findings on domestic violence against the elderly. Social Problems, 33, 146-158.

Pillemer, K. (1986). Risk factors in elder abuse: Results from a case control study. In K. Pillemer \& R. Wolf (Eds.), Elder abuse: Conflict in the family (pp. 239-263). Dover, MA: Auburn House.

Pillemer, K., \& Finkelhor, D. (1988). The prevalence of elder abuse: A random sample survey. The Gerontologist, 28, 51-57.

Quinn, M., \& Tomita, S. (1997). Elder abuse and neglect: Causes, diagnosis, and intervention strategies. New York, NY: Springer.

Roberto, K., Teaster, P., \& Duke, J. (2004). Older women who experience mistreatment: Circumstances and outcomes. Journal of Women \& Aging, 16, 3-16.

Schäfer, W., Kroneman, M., Boerma, W., van den Berg, M., Westert, G., Devillé, W., \& van Ginneken, E. (2010). The Netherlands: Health system review. Health Systems in Transition, 12, 1-229.

Slaets, J. (2006). Vulnerability in the elderly: Frailty. Medical Clinics of North America, 90, 593-601.

Starr, R. (1988). Physical abuse of children. In V. Hasselt, R. Morrison, A. Bellack, \& M. Hersen (Eds.), Handbook of family violence. New York, NY: Plenum Press.

Steinmetz, S. K., \& Anisden, D. (1983). Dependent elders, family stress and abuse. In T. Brubaker (Ed.), Family Relationships in Later Life. California, CA: Sage.

Stevenson, M. (2009). Elder abuse alert: Considerations about a hidden problem. Blacksburg: Virginia Cooperative Extension, Virginia State University.

Straus, M., Gelles, R., \& Steinmetz, S. (1980). Behind closed doors: Violence in the American family. Garden City, NY: Anchor.

Thornberry, T., \& Henry, K. (2013). Intergenerational continuity in maltreatment. Journal of Abnormal Child Psychology, 41, 555-569. 
van Bodegom, D., Bonneux, L., Engelaer, F., Lindenberg, J., Meij, J. J., \& Westendorp, R. (2010). Dutch life expectancy from an international perspective. Leiden, The Netherlands: Leyden Academy on Vitality and Ageing.

Walker, L. (1984). The battered woman syndrome. New York, NY: Springer.

Wolf, R. (2000). Elder abuse: An introduction. Generations, 20, 301-305.

World Health Organization. (2002). Active ageing: A policy framework. Geneva,

Switzerland: Author. Retrieved from http://whqlibdoc.who.int/hq/2002/who nmh_nph_02.8.pdf

Zarit, S., Reever, K., \& Bach-Peterson, J. (1980). Relatives of the impaired elderly: Correlates of feelings of burden. Gerontologist, 20, 649-655.

\section{Author Biographies}

Yuliya Mysyuk, MA, MSc, is a PhD candidate at the Leyden Academy on Vitality and Ageing. Her research project focuses on perspectives on elder abuse in the Netherlands. She has successfully completed the master's program on vitality and aging. Besides this, she acquired her master's degree in public health at Maastricht University and another master's title in sociology and social work at Kyiv-Mohyla Academy in Ukraine.

Rudi G. J. Westendorp, $\mathrm{MD}, \mathrm{PhD}$, is a professor of Medicine at Old age at Copengagen University. From 2005 to 2012, he headed the Department of Gerontology and Geriatrics of the Leiden University Medical Centre. Since 2008 he is a founder and executive director of Leyden Academy on Vitality and Ageing. He is also a member of a large number national and international committees and advisory boards and has published more than 500 articles.

Jolanda Lindenberg, $\mathrm{PhD}$, is a sociocultural anthropologist. She obtained her $\mathrm{PhD}$ from the Max Planck Institute of social anthropology in Germany. Currently, she works as a scientific staff member at the Leyden Academy on Vitality and Ageing. Her current research interests are focused on exploring and analyzing social networks and group identity of older adults. 